\title{
DAVID MAMET: ENTRE EL GUIÓN TEATRAL Y LA NARRATIVA VISUAL
}

\author{
Catalina Buezo Canalejo \\ Universidad Europea de Madrid \\ c.bueno@esp.fil.uem.es
}

Las abundantes estructuras reiterativas y circulares de la comedia cultivada por David Mamet, el dramaturgo, guionista y cineasta estadounidense que mejor ha sabido retratar las pulsiones internas de Norteamérica como nación en las dos últimas décadas, remiten en última instancia a los cuentos de hadas y al mundo de los sueños. No obstante, ni las obras dramáticas ni los guiones cinematográficos de Mamet son fábulas consolatorias, sino una manera de mostrarnos que ni siquiera ahí, en la ficción. la utopía es posible (Buezo, 1998: 195-207). No lo es, de hecho, en el ámbito idílico de un pueblecito de Vermont, elegido por un director de Hollywood y su equipo como escenario para el rodaje de la película El viejo molino (The Old Mill). Pero volveremos sobre el análisis del filme State and Main (2000) más adelante.

El hombre contemporáneo necesita encontrar certezas en un mundo que se desmorona. El Sueño Americano (Buezo, 1998: 69-88), ligado a la conquista del Oeste, la pérdida de la estabilidad familiar, simboli- 
zada en Superman, el héroe estadounidense por antonomasia, y la infancia como mundo feliz son algunos de los tópicos que el dramaturgo analiza y subvierte en su producción dramática. Destacan, en este sentido, piezas como American Buffalo (El búfalo americano, 1977), Glengarry Glen Ross (1984), Reunion (Reunión, 1979) o The frog prince (El príncipe rana, 1983). Al igual que sus obras dramáticas, sus guiones cinematográficos - desde The Verdict (Veredicto final, 1982) pasando por The Untouchables (Los intocables de Eliot Ness, 1985) y We're No Angeles (Nunca fuimos ángeles, 1990) hasta House of Games (Casa de juegos, 1988) y Hoffa (Hoffa, 1992)- son reflejo del subconsciente colectivo estadounidense.

Ahora bien, Mamet, que durante años ha descrito el colapso moral de su tiempo a través de la presentación de ciudades violentas, lagos contaminados, etc., lo que le ha llevado a ironizar en torno a los mitos que conforman ese subconsciente colectivo echando mano en la pantalla de los tonos ocres brindados por el cine negro, en los últimos tiempos, y en concreto desde The Spanish Prisoner (La trama, 1997), ha dulcificado la puesta en escena de su filmografía. Del mismo modo, el lenguaje fragmentario y ácido de los personajes, a base de consignas, eslóganes y frases extraídas de los medios de comunicación, en especial de los seriales televisivos, ha dado paso, como se preludia en The Winslow Boy (El caso Winslow, 1999) y se observa expresamente en State and Main, al diálogo amoroso.

El engaño y el robo, tan presentes en la comedia como género, perviven, empero, como los móviles habituales de unas figuras que ya no se ubican, o no exclusivamente, en la ciudad de Chicago. Mamet hace extensible al cine la capacidad de influir indirectamente en el público, heredada de las revue plays de Chéjov, de Beckett y de Pinter. Al igual que en el teatro, en la pantalla grande se aborda aquello que no puede ser tratado de forma racional, si bien el propio autor considera que una obra dramática y una cinematográfica son objetos artísticos antitéticos. Por medio de la acción de los personajes es posible expresar la acción contenida en la trama, mientras que en una película la acción ha de avanzar desde un punto de vista narrativo, teniendo en cuenta las nociones de progresión visual y de yuxtaposición objetiva de planos a la manera de Eisenstein, a quien considera su maestro.

La trasposición cinematográfica de obras específicamente teatrales, de escaso movimiento y de acción interna, como Glengarry Glen Ross y $E l$ búfalo americano (un filme doméstico salvado por la pericia interpretativa de Dustin Hoffman como Teach) pone de manifiesto la 
dificultad y el reto de un Mamet guionista que apuesta por la revisión irónica de géneros recibidos. Ya en su debut como director-autor en Casa de juegos, como un hábil jugador profesional o con man, Mamet reparte cartas trucadas al espectador, situación que años más tarde lleva al extremo en La trama, también dentro del género del thriller. La habilidad de su arte reside en el ingenio verbal, en un argumento falaz y en unos personajes de acción engañosa que despistan al auditorio, si bien a veces el espectador avisado acaba notando el artificio y espera una nueva vuelta de tuerca en el guión. Por fortuna, las secuencias lingüísticamente simétricas de Casa de juegos dejan paso a paralelismos visuales que configuran un estilo propio en Homicide (Homicidio, 1990), filme con el que Mamet adquiere autonomía estética. Aquí, las piezas de un guión, concebido a modo de puzzle, ya no encajan a costa de la verosimilitud y Mamet ofrece un final abierto no exento de crítica social: detrás del mito del multiculturalismo perviven tensiones étnicas en buena parte irresolubles.

Al alejarse en Homicidio del montaje rítmico, que da primacía a lo verbal, y optar Mamet cada vez más por un montaje primario, liso, y por un montaje en paralelo, no sólo se distancia nuestro autor del teatro filmado, sino que se acerca a un tipo de narración verosímil que tendrá su correlato en las viñetas narrativas yuxtapuestas que conforman su primera novela, The Village (Esa ciudad tranquila, 1994). Y de esas viñetas parte, en nuestra opinión, cuando se embarca en la aventura de rodar State and Main. Pero comencemos por el principio, es decir, por ese teatro o teatro filmado del que Mamet consigue airosamente salir.

\section{DEL TEATRO Y DEL TEATRO FILMADO}

El fenómeno teatral puede ser definido, en principio, como una estructura múltiple de signos que se desarrollan en diferentes niveles. A comienzos del siglo y sobre todo en el período de entreguerras comienza, en torno al Círculo Lingüístico de Praga, la reflexión sobre el teatro desde una óptica semiótica. A partir de la consideración del arte como un hecho semiológico, por parte de Mukarovski, los hombres de teatro checos definirán la acción dramática como una estructura de signos que en cada situación debe mantener su equilibrio. Desde entonces, se establecen los rasgos más característicos del signo teatral. 
Para un estudio casi exhaustivo de los «códigos teatrales», el cuadro de trece sistemas propuesto por Kowzan resulta útil, aceptando que su clasificación es, como todas, arbitraria y que el número de sistemas podría reducirse. Su propuesta emplea criterios teatrales, desde el punto de vista teórico y de la práctica escénica: visual-auditivo, tiempo-espacio, actor-no actor, y de forma implícita se refiere al espectador (Kowzan, 1975). Seguidamente pasamos a analizar la dramaturgia de Mamet, centrándonos sobre todo en Glengarry Glen Ross y teniendo presente el mencionado cuadro semiológico de Kowzan.

\subsection{El texto dramático: la palabra}

Presupone el aparte parentético cierta complicidad con el público, al ser un discurso del personaje dirigido a sí mismo (y por lo tanto, al auditorio) que muestra la verdadera intención de éste. Abunda en las primeras piezas del autor y desaparece casi por completo en Glengarry Glen Ross, donde únicamente encontramos el siguiente caso: «ROMA (Hablando consigo mismo.) Los jodidos Mitch y Murray se van a cagar... qué voy a hacer todo...» (GGR: 167). Parece aquí tratarse de algo que el personaje se dice a sí mismo a modo de monólogo interior que sólo el espectador conoce.

Este tipo de soliloquio psicológico, que puede asimismo tener un propósito enfático o aclaratorio o dar cuenta de la desintegración psíquica de un personaje, es cuantitativamente menor si lo comparamos con el acto de contar o storytelling. Otra manera de dirigirse el actor al público, ésta ya directamente, es no a través del aparte sino de la apelación, sobre todo al final. No se trata de una invocación a actuar correctamente, como en el milagro medieval, sino de un intento de enlazar la ficción teatral y la situación concreta de los espectadores. Se da especialmente en obras para niños y en piezas metateatrales como A Life in the Theatre (Una vida en el teatro, 1977), donde la distancia entre los actores y el auditorio es escasa. Con todo, este tipo de presentación directa que presupone la eliminación de la cuarta pared aparece en raras ocasiones: a Mamet le interesa que avance la acción y considera que cualquier embellecimiento que la retarde debilita la obra (Bigsby, 1985: 26). A continuación, centrándonos sobre todo en Glengarry Glen Ross, procederemos al análisis de los signos no lingüísticos. 


\subsection{Los signos no lingüísticos: minimalismo y anomia}

\subsubsection{El tono: entre la energía y la resignación}

No se menciona en las acotaciones el término «tono», si bien hay que sobrentenderlo cuando Roma baja la voz al hablar con Lingk. En algún caso se alude al jadeo, al cansancio o a la desesperación con que hablan los personajes. En su perplejidad y desamparo, Lingk llega a tartamudear en presencia de Roma («Per.. perdona... porque... ya no sé nada de nada», GGR: 189). A veces, en fin, los personajes susurran, refunfuñan, suspiran o emplean un tono declamatorio, si bien por lo general, dado el dinamismo escénico de la comedia, los parlamentos se enuncian con rapidez.

Por otra parte, no resultaría extraño que determinados personajes declamaran a voces o impetuosamente. Se sobreentiende que las palabras que en el texto aparecen en mayúsculas o en cursiva exigen determinado tono y ritmo en la lectura. A nuestro entender funcionan a modo de acotaciones implícitas del tipo «alzando la voz»o «enérgicamente» («ROMA ( $a$ WILLIAMSON). Se te contrata para que nos ayudes ite queda claro? Para que nos ayudes», GGR: 189). Corrobora lo anterior el encontrar mayúsculas en The Revenge of the Space Pandas (La venganza de los pandas del espacio, 1978) justamente cuando George Topax, el jerarca máximo, ordena detener la ejecución de Vivian y Binky («GEORGE. PARA LA EJECUCIÓN!», TROTSP: 115).

\subsubsection{Mímica y gesto: el absurdo situacional}

Frente a la esfera de la improvisación, se levanta en el terreno de la mímica una cierta tradición gestual. Hay gestos procedentes de la realidad, como las salidas apresuradas; otras veces se trasponen a la escena gestos formalizados que parten del ceremonial, como la invitación a tomar asiento, $y$ hay, por otra parte, ciertos gestos que pueden haber pertenecido a la esfera de la vida cotidiana, y que el teatro ha retenido, o se pueden haber gestado en el propio teatro. Finalmente, un actor en su actuación puede remitir a una determinada escuela, como 
Brando o Al Pacino, en quienes no podemos pensar sin asociarlos al method acting.

Pero junto a Al Pacino, habitual en los papeles mametianos de Teach o de Roma tanto en teatro como en cine, se erige toda una nómina de actores anónimos que con el tiempo cobran relevancia porque reaparecen una y otra vez en las producciones del dramaturgo por deseo expreso de éste, como es el caso de William H. Macy. Al elegir Mamet para sus montajes actores alejados del star system participa del concepto brechtiano de que lo que se cuenta es más importante que el individuo que lo muestra; pero junto a esto, se encuentra la postura contraria, la del autor que, presionado por Broadway o por las exigencias de la pantalla grande, echa mano de comediantes consagrados junto a miembros de su nómina habitual, como es el caso de la pareja formada por William H. Macy y Alec Baldwin en State and Main.

En Mamet, al igual que en Beckett - frente a lo que en principio podría parecer- el absurdo es más situacional que metafísico. Si a los espectadores de Esperando a Godot se les transmite la sensación de aburrimiento que experimentan los personajes a la espera de un tal Godot que nunca llega, de idéntica manera Mamet transmite la desazón y ansiedad que sufren sus caracteres al auditorio sentado en el patio de butacas. Así, encontramos en Glengarry Glen Ross desde el desconocimiento que se expresa con un encogerse de hombros, hasta el asentimiento que conlleva un movimiento de cabeza, pasando por la ojeada rápida, el rebuscarse los bolsillos en busca de dinero o el acomodarse en el asiento, y a veces se trata de toda una gesticulación fingida para despistar y derrotar al adversario.

\subsubsection{Movimiento: obras estáticas de dialéctica verbal}

En Mamet el dinamismo verbal contrasta con un estatismo físico que se intensifica en piezas como Glengarry Glen Ross, especialmente en el primer acto: las figuras no recorren el tablado y se limitan a tomar asiento (Peereboom, 1989: 189-92), idea unida a la del descanso. Los cambios escénicos en Glengarry Glen Ross se producen con la entrada o salida de personajes en escena, como es habitual, y asimis- 
mo cuando el detective Baylen asoma la cabeza por la puerta de su despacho y llama a los vendedores para ser interrogados.

\subsubsection{Maquillaje, indumentaria y peinado estereotipados}

No encontramos apenas acotaciones referentes a peinado o a maquillaje, que podemos imaginar en algunos casos cuando se alude a la indumentaria de ciertos caracteres. Así Karen, personaje representado por Madonna en Speed-the-Plow (1988), no saldría a escena como la asexuada doctora Ford de Casa de juegos - cuyo cambio de vestuario sirve para reforzar las estructuras narrativas y temáticas del filme (Brewer, 1993: 26-27) y para trazar la evolución psicológica del personaje—, sino con la sofisticación y feminidad de la secretaria prototípica, que, sin embargo, no se ajusta en su comportamiento a ese estereotipo.

Por su parte, en Bobby Gould in Hell (Bobby Gould en el infierno, 1991) el diablo entra con barba roja y botas de goma, dispuesto a irse de pesca, y el dramaturgo juega con la afición del personaje por este deporte y su carácter alegórico, como pescador de almas. En cualquier caso, de este dato se infiere que a personajes presumiblemente estereotípicos, como los vendedores inmobiliarios de Glengarry Glen Ross, les corresponde un maquillaje, un peinado y una indumentaria reconocibles por el auditorio - salen al tablado repeinados y con traje-, que se ve sorprendido luego por el lenguaje que emplean, no por su presencia física.

\subsubsection{Iluminación: de la luz diurna al claroscuro}

Por lo general, las obras mametianas se escenifican de día, y ocurre de noche lo que pertenece al dominio de la imaginación, de la fantasía o de lo prohibido. Así, el robo perpetrado en Glengarry Glen Ross, que acontece, además, fuera del tablado entre el primer y el segundo acto. En The Cryptogram (El criptograma, 1994) el apagón final está ligado al estado mental del personaje de John y a su posible suicidio en una obra llena de temores y miedos, escenificada de noche en el salón de estar familiar. También en Squirrels (Ardillas, 1982) la iluminación nocturna se vincu- 
la a los fondos irracionales de la mente, orientada no ya a la autodestrucción, sino, en un sentido positivo, a la creatividad literaria.

\subsubsection{Accesorios: escasez de elementos y caracterización}

En el propio texto se puede dar cuenta de los accesorios empleados en un momento de la pieza (los teléfonos de Glengarry Glen Ross; una mesa de mezclas de un estudio de radio, auriculares y micrófono en Four A. M., Cuatro de la mañana, 1985), o de la importancia de uno en particular para la acción dramática. De ahí que leamos en Glengarry Glen Ross: «La oficina inmobiliaria. Saqueada. Una ventana rota y tapiada, cristales por el suelo», GGR: 163). La duplicidad de los personajes exige el uso del teléfono, que se convierte en parte integrante de la trama en Glengarry Glen Ross, sobre todo en su versión fílmica.

El comienzo de Oleanna (1994), con un John preocupado por la propiedad inmobiliaria, parece un fragmento extraído de Glengarry Glen Ross («...has llamado a Jerry? [...] Has hablado con la agencia inmobiliaria..?», $O: 1)$. De nuevo observamos cómo la obra mametiana conforma un microcosmos que remite una y otra vez a sí mismo, puesto que uno de los personajes de Glengarry Glen Ross, también presentado indirectamente, por boca de otros, recibe asimismo este nombre (Jerry Graff). En el ejemplo anterior, el teléfono no sólo no propicia sino que interrumpe la comunicación, como también sucede en la escena inicial de Speed-the-Plow. Esto es así porque los objetos que ocupan la escena suelen tener una función doble: la de caracterizar a los personajes y la de participar en la acción dramática.

Finalmente, hay objetos que adquieren la categoría de símbolos; ayudan a que el autor administre perfectamente el pathos en el escenario. Así, en El criptograma, el sobre blanco que contiene una misiva por medio de la cual Robert notifica a Donny que la abandona, al final del primer acto; la vela ardiendo en la oscuridad al fin del segundo acto; el cuchillo que empuña John al concluir la representación. La propia manta que cobija a John y le resguarda del frío, asociada al amor que en otro tiempo sus padres se tuvieron. Con todo, el carácter incierto y ambiguo de esta obra, como por otra parte es habitual en Mamet, explica que también estos símbolos sean polivalentes. Por consiguiente, el cuchillo es un recuerdo bélico; un símbolo de la trai- 
ción del padre; un regalo de despedida; una premonición de la muerte (Feingold, 1995: 97).

\subsubsection{Sonido: pausas, subtexto y catarsis}

En el teatro mametiano la sobreabundancia de ruidos se limita a las piezas para niños, donde se recrea una atmósfera festiva por medio de la presencia de silbatos, trompetas, bocinas o tambores. Ahora bien, en el resto de las obras del autor, la llamada «comedia mametiana» que venimos analizando, el minimalismo objetual corre parejo con la escasez de ruidos y la total ausencia de instrumentos y canciones. De ahí que la imaginación del espectador deba suplir escenas que ocurren dentro y de las que se nos informa gracias al diálogo de los personajes. Poco o nada nos dicen las acotaciones escénicas: una puerta se cierra con violencia en Glengarry Glen Ross; un teléfono interrumpe una conversación aparentemente distendida en Speed-the-Plow y en Oleanna, o una tetera se le rompe a Donny fuera de escena en El criptograma.

Por otro lado, en el teatro de Mamet lo más importante ocurre en los entreactos (el robo en Glengarry Glen Ross; la «conversión» de Gould en Speed-the-Plow, vgr.), al tiempo que el espectador capta cómo media un abismo entre lo que el personaje realmente siente (el amor de Levene a una hija a la que apenas puede ver a causa de su trabajo) y lo que expresa a través de un lenguaje manido y fragmentario (la necesidad de mantener a esa hija le empuja luego al delito). Matthew C. Roudané, después de reflexionar en torno a una cita extraída de $L a$ trama, llega a la conclusión de que el héroe mametiano a menudo siente que tiene derecho a «explotar» en un mundo en el que la mirada fría y desapasionada resulta insatisfactoria (1986: 35-47). Ese derecho a la catarsis, ese acto de liberación, se lleva a cabo en el subtexto, en los intersticios, que Roudané denomina «carnivalesque play spaces» porque comparten con la atmósfera carnavalesca cierto efecto de purificación, de expulsión de todo lo que ha permanecido contenido por el efecto restrictivo de las normas sociales. Precisamente éste es uno de los mayores logros de Mamet: su habilidad para sugerir lo que subyace bajo la superficie, para percibir que la comunicación tiene frecuentemente menos que ver con las palabras que empleamos que con la empatía silenciosa que se crea entre los hablantes. 
1.2.8. Decorado: cuerpo humano y «homelessness»

Para Mamet el decorado es, en primer lugar, verbal: el público ha de imaginar por medio del diálogo entre los personajes la chatarrería de El búfalo americano o el laboratorio casero de The Water Engine (El motor de agua, 1978). O la oficina inmobiliaria de Glengarry Glen Ross y el despacho universitario de Oleanna, obras que comparten una misma utillería escénica, puesto que ésta se reduce a unas sillas, unas mesas y una pizarra. En Goldberg Street (1985) el minimalismo escénico llega a su punto máximo: ni siquiera los actores cambian de indumentaria al salir a las tablas.

Ahora bien, si algo define el espacio escénico mametiano es su homelessness, la disociación de los caracteres de la naturaleza y de lo doméstico, lo que le distancia de obras canónicas como Largo viaje hacia la noche, de Eugene ONeill, Muerte de un viajante, de Arthur Miller o Un tranvía llamado deseo, de Tennessee Williams. El segundo acto de Speed-the-Plow, el nudo, tiene lugar significativamente en casa de Bobby Gould a la caída de la tarde: durante «the blue hour» y en la intimidad los personajes mametianos son más vulnerables. Rara vez es el hogar el lugar escénico elegido. En la segunda fase de su dramaturgia, sin embargo, el salón de estar familiar del teatro realista, desde Ibsen hasta Arthur Miller, reaparece como escenario posible en El criptograma y Passover (1995).

Durante los ensayos Mamet reescribe algunas escenas y elimina otras (Nuwer, 1985: 1-7), porque lo que no funciona en un escenario debe descartarse. Sus tres premisas básicas son ser honesto, directo y lo más sencillo posible (Savran, 1988: 139). Dennis Carroll (1987: 118-39) dedica un capítulo de su monografía a los problemas de lectura que una obra de Mamet puede generar: cualquier director de escena se encuentra ante textos elípticos y ambiguos, sujetos a diferentes interpretaciones. Comenta Mamet a este respecto que la verdadera intención del personaje se entrevé por el ritmo del diálogo, que puede dejar al descubierto intenciones que se contraponen al significado de las palabras. De ahí que una escenografía realista o metafórica acabe siendo una opción individual. En el caso de Glengarry Glen Ross, 1a escenografía de Michael Merritt para el montaje de Mosher se decantó por una puesta en escena realista, mientras que la de Hayden Griffin para la producción de Bryden ofreció un segundo acto de corte expresionista (la luz, como entre los barrotes de una celda, se filtraba por la ventana y las paredes de la saqueada oficina). 


\section{STATE AND MAIN (2000): ENTRE EL GUIÓN TEATRAL Y LA NARRATIVA VISUAL}

Partiendo de la idea de que las elecciones se ganan por televisión y del poder manipulador de este mass media, Mamet escribió en colaboración, en 1996, el guión de Wag the Dog (La cortina de humo, 1997), una comedia irónica e ingeniosa como pocas. En diferentes escenas vemos la verdadera realidad que se oculta detrás de las cámaras. Así, Brean compra a un periodista, Sklansky, para que en la rueda de prensa pregunte si la permanencia del presidente norteamericano en China no tiene que ver con la situación que se vive en Albania. Más tarde aparece por televisión una actriz en el papel de joven albanesa torturada por terroristas de su país, debido a que su familia tiene conexiones con Canadá, por cuya frontera con Estados Unidos ese grupo de disidentes intenta infiltrar un maletín con una bomba.

La actriz rueda una toma con una bolsa de patatas fritas en la mano, que luego será convenientemente sustituida por un gatito. Se adereza el montaje haciéndola finalmente correr por un puente en llamas, con sonido de sirenas para dar más dramatismo. Esa misma muchacha, y una anciana que simula ser su abuela, presumiblemente liberadas, acuden a dar la bienvenida al presidente cuando llega a suelo norteamericano. Llueve copiosamente y el primer mandatario cubre con su abrigo a la vieja. Se acaba el rodaje y vemos cómo la lluvia era artificial y en realidad hace un día espléndido.

Norteamérica es un estado de opinión creado por los mass media, idea sobre la que se abunda en State and Main, y uno de ellos es el cine, que crea expectativas en los aparentemente tranquilos habitantes del pueblecito de Vermont, elegido por Walt Price (William H. Macy) como lugar de rodaje. La cámara nos presenta cómo Walt llega al pueblo y se instala en el hotel como base de operaciones; pero pronto descubrimos que el personaje sobre el que pivota esta obra coral es Joseph Turner White (Philip Seymour Hoffman), quien debe reescribir el guión de El viejo molino (debido a que se incendió hace años el que todavía figura en las guías locales) y ni siquiera tiene máquina de escribir. La búsqueda de una le conduce sin proponérselo a la librería local y a una relación amorosa con su inteligente propietaria (Rebecca Pidgeon) que sobrepasa los límites del flirteo en un filme que, más allá de la presentación de los entresijos de Hollywood, acaba desembocando en una agridulce comedia de amor. Lejos se encuentra Mamet de la 
presentación de mujeres exuberantes que incitan al deseo (Karen en Speed-the-Plow) o causan rechazo, como la asexuada Oleanna, que en el acto II de la obra homónima, erguida y con aspecto de militante feminista, continúa repeliendo al espectador.

Barry Levinson, el director/ productor de La cortina de humo, considera a Mamet el mejor guionista estadounidense de su generación, el cual, después de la amarga experiencia con los productores de Los intocables de Eliot Ness, un filme repleto de guiños comerciales, se decantó por el modelo de producción independiente al pasarse al terreno de la realización. Incluso en correctas adaptaciones de novelas ajenas en los casos de Veredicto final y The Postman Always Rings Twice (El cartero siempre llama dos veces, 1981), hay un trasfondo de conflicto moral que les confiere una profundidad que va más allá de lo puramente anecdótico.

Otro tanto se puede decir de State and Main, título que remite a la encrucijada de calles, en la cual tiene lugar el accidente automovilístico que presencia Joseph, el guionista, como único testigo. Su encrucijada moral será, a partir de entonces, o dejar atrás sus creencias personales y pensar en su carrera, como le indican el director y el productor del equipo, o seguir los dictados de su conciencia. Su nuevo amor le invita a tomar esta postura y a testificar en contra del automovilista (la celebridad del reparto, Bob Barrenger, papel interpretado por Alec Baldwin), que llevaba en el asiento del copiloto a una adolescente del lugar (Julia Stiles) con la que ha empezado a mantener relaciones.

El filme, repleto de frases memorables como «La única segunda oportunidad que conozco es la oportunidad de cometer el mismo error dos veces», da, sin embargo, esa segunda oportunidad a todos los caracteres: en Joseph, tras un simulacro de testificación orquestada por Rebecca Pidgeon, vencen el amor y la ética; Walt consigue que los cargos contra Bob se retiren (vemos un plano del ex-prometido de la dueña de la librería sonriente ante una cámara de televisión que muestra su torso, mientras sostiene en las manos el maletín con el dinero del soborno) y la película, abortada en otra población similar, se rueda ante los complacidos habitantes, que también han tenido una segunda oportunidad después de la oleada de incendios y vandalismo que destrozó el pueblo años atrás, presente en la memoria colectiva. Como en Una ciudad tranquila, primera novela del autor, por medio de la yuxtaposición de diversas historias entra el espectador en contacto con una pequeña comunidad en la que todo el mundo se conoce y donde en 
apariencia no ocurre nada, a pesar de lo cual la tragedia está siempre rozando lo cotidiano e insustancial.

Ese final es, con todo, irónico, un tributo al cinematógrafo como fábrica de sueños, de momentos felices que se sostienen en equilibrio antes de la catástrofe, porque sabemos que Bob volverá a correr detrás de otra menor en su siguiente película $y$, al igual que la empresa de suministros informáticos que esponsoriza parte de la producción a cambio de publicidad encubierta (el logotipo aparece solapado en una escena de época), el dinero acallará los rumores. E intuimos que Sherry nuevamente hará gala de prejuicios varios para no mostrar los pechos en pantalla, si bien no tiene inconveniente en hacer el amor con buena parte del equipo, o que el compromiso de Joseph con lo que cree justo es una actitud interior sujeta a las flaquezas de la condición humana.

Esas mismas flaquezas revierten en el «tiempo cinematográfico»: cuando el rodaje de El viejo molino se estanca, el espectador tiene la sensación de que el filme en conjunto se ralentiza; parece, en ocasiones, acercarse al estatismo de un guión escrito para el teatro que se ha llevado al celuloide con apenas modificaciones: los diálogos pugilísticos, tan mametianos, recuerdan a los de Glengarry Glen Ross o de Sexual Perversity in Chicago (Perversidad sexual en Chicago, 1978). Nos encontramos con lo que más arriba denominábamos situaciones de absurdo situacional, y participamos, por medio de un montaje deliberado, de la desazón y de la incertidumbre que se apoderan de los caracteres.

Mamet es consciente de la capacidad manipuladora del montaje, a un tiempo un fenómeno estético de análisis y síntesis, como hicieron constar Poudovkin, Eisenstein y Alexandrov en el Manifiesto firmado en Leningrado en agosto de 1928. Por ello, Mamet, que se confiesa un hábil jugador de póquer, gracias al juego del montaje consuma el engaño a los sentidos a los que nos tiene acostumbrados en una película donde los paralelismos son tanto verbales como visuales (el leit-motiv de mostrar o no los pechos parece repetirse visualmente en una serie de objetos que, ya en casa del alcalde ya sobre la chimenea, bien pudieran tener este simbolismo). En efecto, alternando los diferentes puntos de vista de la cámara, eligiendo el contenido de cada movimiento y el tiempo o medida relacionados con el contenido, crea un «tiempo cinematográfico» que lleva aparejado un ritmo específico en función de la ligazón de las imágenes, de su continuidad y de su duración. 
Lejos de la iluminación de tono bajo, habitual en el género del psycothriller y presente en Casa de juegos y Homicidio, o del juego expresionista con el color que veíamos en Glengarry Glen Ross, luces anaranjadas que inciden en el rostro de los vendedores al lado de rótulos de neón rojos y azules, ahora es la vida diurna de un pueblo cualquiera la que se retrata; pero esta imagen de papel cartón, tan del gusto de los directores de Hollywood, esconde un polvorín. El sonido en off -el avión que despega y que no coge Mike en Casa de juegos; el avión que lleva al abogado de Walt, el director de cine, hasta el lugar del rodaje con el maletín del dinero - sugiere un espacio que se extiende más allá de la acción visible, un ámbito de donde procede la solución a los problemas que mantienen a los caracteres en un círculo vicioso.

Madonna interpretó para la escena el papel de Karen en Speed-thePlow. A la salida, el público, según Gregory Mosher, director del montaje, no podía dejar de preguntarse: «Is she an angel? Is she a whore?» (Henry, 1988: 99). El propio Mosher no sabe muy bien si en la obra se hace una crítica de Hollywood o una apología cínica, y en la misma línea se halla la opinión de Mel Gussow (1988: 5-55), para quien el autor se muestra tan cínico con quienes quieren redimir al prójimo como con los que desean arruinar nuestras vidas. Esta afirmación vale también para State and Main.

\section{Referencias bibliográficas}

\section{a) Libros:}

Bigsby, C. W. E. (1985). David Mamet. Londres: Methuen.

Brewer, G. (1993). David Mamet and Film: Illusion / Disillusion in a Wounded Land. Jefferson y Londres: McFarland.

CARroll, D. (1987). David Mamet. Houndmills: MacMillan.

KowZAN, T. (1975). Littérature et spectacle dans leurs rapports esthétiques, thématiques et sémiologiques. La Haya: Mouton.

MAMET, D. (1995). Esa gente tranquila. Madrid: Debate.

\section{b) Volúmenes colectivos:}

Buezo, C. (1999). «El Chicago de David Mamet, extensión de la vida onírica». En Perspectivas de la ciudad, Catalina Buezo (coord.), 95-110. Madrid: Universidad Europea-CEES. 
Peereboom, J. J. (1989). «Mamet from Afar». En New Essays on American Drama, Gilbert Debusscher y Henry I. Schvey (eds.), 189-199. Amsterdam: Rodopi.

\section{c) Artículos:}

BuEzo, C. (1998a). «La imposible Arcadia idílica de los relatos infantiles de David Mamet». Estudios ingleses de la Universidad Complutense 6, 195207.

- (1998b). «Subversión y destrucción del mito del Sueño Americano: The Water Engine, American Buffalo y Glengarry Glen Ross, de David Mamet». En Ensayos de literatura norteamericana contemporánea, 69-88. Madrid: Universidad Europea-CEES.

— ed. (2000). David Mamet. «Glengarry Glen Ross». «Casa de juegos». Madrid: Cátedra.

FEINGOLD, M. (1995). «Codehearted». Voice, 25 April, 97.

Gussow, M. (1988). «Mamet's Hollywood Is a School for Scoundrels». New York Times, 15 de mayo, sec. 2, 5-55.

HenRY, W. H. III (1988). «Madonna Comes to Broadway». Time, 16 May, 99.

NuwER, H. (1989). «A Life in the Theatre: David Mamet». Rendezvous: Journal of Arts \& Letters 2, 1 (Fall) 1-7.

SAVRAN, D. (1988). «David Mamet». En In Their Own Words, 132-144. Nueva York: Theatre Commmunications Group. 